Received 00th January 20xx, Accepted 00th January 20xx

DOI: $10.1039 / x 0 x x 00000 x$

\section{Concise asymmetric synthesis of new enantiomeric $C$-alkyl pyrrolidines acting as pharmacological chaperones against Gaucher disease}

Tessa Castellan, ${ }^{a}$ Virginie Garcia, ${ }^{\mathrm{b}}$ Frédéric Rodriguez, ${ }^{\mathrm{a}}$ Isabelle Fabing, ${ }^{\mathrm{a}}$ Yevhenii Shchukin, ${ }^{\mathrm{a}}$ My Lan Tran, ${ }^{\text {a }}$ Stéphanie Ballereau, ${ }^{a}$ Thierry Levade, ${ }^{b}$ Yves Génisson, ${ }^{a}$ Cécile Dehoux*a

\section{Introduction}

Gaucher disease (GD), the most prevalent lysosomal storage disease, is caused by the deficient activity of the lysosomal $\beta$ glucocerebrosidase ( $\beta$-GCase). The deficiency of this acid hydrolase leads to the primary accumulation of glucosylceramide in the lysosome. ${ }^{1}$ Three clinical types of GD are distinguished depending on the early or late onset of the disease and on the severity of the symptoms ranging from visceral manifestations to neurological damages. In the most common type referred as type 1, manifestations concern mainly viscera (spleen and liver enlargement) and bone marrow. The type 2, also called acute infantile neuronopathic GD, has the earliest onset of all GD types. The type 3, also known as chronic neuronopathic GD, is characterized by a later and more gradual onset. Patients survive until adulthood with a wide variety of signs and symptoms including neurological involvement. ${ }^{2}$ The observed deficiency of $\beta$-GCase activity is due to mutations in the GBA1 gene which often lead to misfolding of the protein, as well as abnormalities in its intracellular trafficking and delivery to the lysosome. More than 350 mutations of GBA1 have been reported for GD patients (From Human Gene Mutation Database (HGMD): http://www.hgmd.cf.ac.uk/ac/index.php), the N370S and L144P missense mutations being the most frequent. The N370S substitution results in a sufficient residual activity of $\beta$-GCase to allow the catabolism of glucosylceramide in neurons. Thus, patients carrying the N370S mutation do not exhibit neurological manifestations and are affected with type $1 \mathrm{GD}$. In contrast, the L144P mutation leads to a neurological form of the disease and is linked to GD types 2 and 3.

a.SPCMIB, UMR5068 CNRS-Université Paul Sabatier-Toulouse III, 118 Route de Narbonne, F-31062 Toulouse, France. E-mail: baudoin@chimie.ups-tlse.fr (C.D.)

b. Institut National de la Santé et de la Recherche Médicale (INSERM) UMR1037, Centre de Recherches en Cancérologie de Toulouse (CRCT), Université Paul Sabatier, Laboratoire de Biochimie Métabolique, Institut Fédératif de Biologie, $\mathrm{CHU}$ Purpan, F-31059 Toulouse, France.

+ Electronic Supplementary Information (ESI) available: Copies of NMR spectra of new compounds; NOESY NMR analyses of compounds 2 and 3; Dose-response curves of compounds $\mathbf{2}$ and ent-2 versus $\beta$-GCase; Lineweaver-Burk plots for compounds $\mathbf{2}$ and ent-2 versus $\beta$-GCase; Comparison of NN-DNJ with best poses of ent-2 and 2; MTT Test for compound 2, ent-2, NN-DNJ and IFG
Two strategies are currently used for the symptomatic treatment of GD. Enzyme replacement therapy (ERT) is the firstline treatment against type 1 and type $3 \mathrm{GD} .^{3}$ The principle of ERT relies on intravenous administration of a recombinant human $\beta$-GCase (Cerezyme ${ }^{\circledR}$, Vpriv $^{\circledR}$, Elelyso ${ }^{\circledR}$ ) to overcome the defect of the endogenous protein. As the recombinant enzyme cannot cross the blood-brain barrier, ERT is inefficient against neurological manifestations. The substrate reduction therapy (SRT) aims at inhibiting glucosylceramide biosynthesis to limit its lysosomal accumulation. In 2015, a new glucosylceramide synthase inhibitor, Eliglustat (Cerdelga ${ }^{\circledR}$ ) was approved for the treatment of type 1 patients. This specific and potent inhibitor brings significant improvements over existing treatments but also fails to cross the blood-brain barrier. Pharmacological chaperone (PC) therapy is an innovative strategy that has been successfully implemented against Fabry disease, another lysosomal storage disease. ${ }^{4} \mathrm{~A}$ PC is a small molecule that, by specifically binding to the misfolded protein, allows its stabilization, prevents its premature degradation by the proteosome and thus improves its trafficking to the lysosome. ${ }^{5,6}$

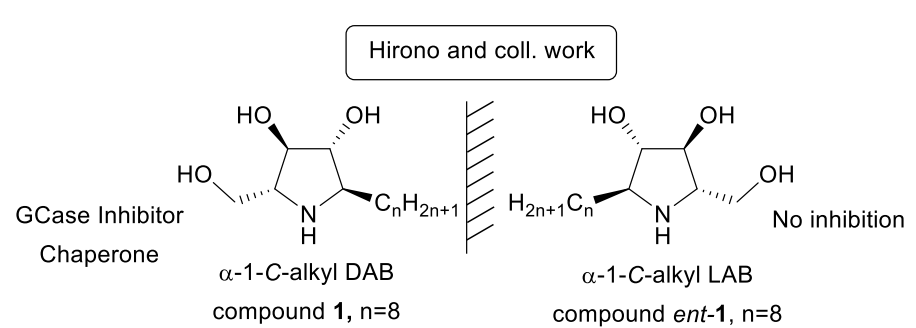

?

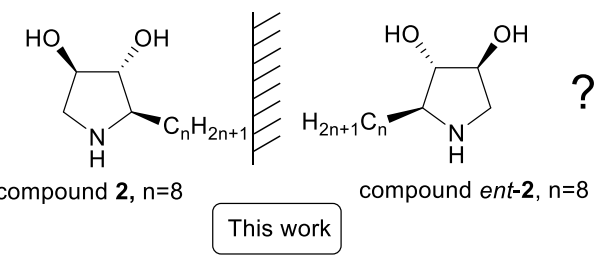

Figure 1. Impact of the chirality and of the hydroxymethyl removal on the $\beta$-GCase inhibition and the chaperone ability 
Most PCs are active-site specific chaperones (ASSC), i.e. are reversible competitive inhibitors of the $\beta$-GCase used at subinhibitory concentrations. The clinical development of such drug candidates, potentially responsible for either enzyme activation or inhibition depending on the dosage regimen, is challenging. ${ }^{7}$ The iminosugar Plicera ${ }^{\circledR}$ (isofagomine D-tartrate) was developed against GD but failed in phase II clinical trials in 2009 due to lack of significant clinical improvement. The noniminosugar, Ambroxol, a well-known drug used as expectorant in the treatment of respiratory diseases, was identified as an effective PC for the treatment of type 1 patients, and is currently being evaluated for type $3 \mathrm{GD} .^{8}$

Recent research efforts have been performed to identify second generation PCs able to stabilize protein without interfering with the hydrolytic activity of $\beta$-GCase. ${ }^{7,9-11}$ The recent identification of an allosteric binding site represents an opportunity for the design of new non-inhibitory chaperones of $\beta$-GCase. ${ }^{12}$ In this perspective, the L-iminosugar series may provide relevant chemotypes. Indeed, since the pioneering work of Fleet, ${ }^{13}$ many enantiomeric pairs of iminosugars have been reported to inhibit the same glycosidase. While the Diminosugars act as competitive inhibitors, the L-enantiomers are in contrast often found to be non-competitive. For instance, Disofagomine (D-IFG) is a competitive inhibitor of $\beta$-GCase whereas its enantiomer proved to be a weaker and noncompetitive inhibitor. ${ }^{13}$ The natural products DMDP, ${ }^{14} \mathrm{DAB}$ and 4-C-methyl-DAB ${ }^{15,16}$ are competitive inhibitors of $\beta$ glucosidases, whereas their L-antipodes are more potent noncompetitive inhibitors of the same enzymes. Similarly, Ldeoxygalactonojirimycin (L-DGJ) and its enantiomer D-DGJ were shown to be respectively non-competitive and competitive inhibitors of the $\alpha$-galactosidase A. ${ }^{17}$ Notworthy, few examples of L-iminosugars also display a significant lysosomal enzyme chaperoning activity. ${ }^{17-21}$ Non-competitive inhibitors, which do not bind to the active site, offer an interesting alternative to active-site specific chaperones.

In this work, we investigated the ability of two new enantiomeric $C$-alkyl pyrrolidines to act as $\beta$-GCase chaperones.
A few years ago, Martin, Compain and coll. reported a gradual PC optimization combining a shift of the aliphatic chain around the heterocyclic core with an overall iminosugar scaffold simplification. Starting from the seminal ASSC $\mathrm{N}$-alkyl deoxynojirimycin, ${ }^{22}$ this work led to the uniquely potent PC series 2-O-alkyl imino-D-xylitol (DIX) lacking the typical glucoselike hydroxymethyl appendage. ${ }^{23-25}$ We envisioned that implementation of such a structural simplification approach to the pyrrolidine PC $\alpha-1-C$-alkyl-DAB reported by Hirono and coll. ${ }^{26}$ could both improve the iminosugar chaperone ability and facilitate its synthetic access. Toward this aim, we first conceived an original and expedient asymmetric route to this simplified 5-membered cyclic pharmacophore. Then we assessed the effect on $\beta$-GCase activity of the enantiomeric pyrrolidines 2 and ent-2 bearing an $n$-octyl chain (Figure 1 ) in the prospect of evaluating the impact of the hydroxymethyl group deletion on the chaperoning ability in both enantiomeric series.

\section{Results and discussion}

\section{Asymmetric synthesis of 2 and ent-2}

We developed a new enantioselective 4-step synthetic sequence allowing the preparation of $\mathbf{2}$ and ent-2 with high yield and optical purity (Scheme 1). Our strategy is based on the asymmetric synthesis of the two aminoallenes $\mathbf{6}$ and ent- $\mathbf{6}$ using a $\mathrm{CuBr}_{2}$-catalysed transformation developed by $\mathrm{Ma}$ and coll... ${ }^{27}$ The reaction between nonanal (4) and $N$-Boc-propargylamine (5) performed in the presence of the appropriate enantiomer of diphenylprolinol and cooper (II) bromide provided the desired aminoallenes 6 and ent-6 with 63-66.5\% yield and 94-96\% enantiomeric excess, as determined by chiral HPLC. ${ }^{\ddagger}$ The intramolecular cyclisation of the aminoallene in presence of $\mathrm{AgNO}_{3}$ led to the pyrroline 7 (or ent-7) with a complete transfer from axial to central chirality, as indicated by the absence of significant erosion of the enantiomeric purity.
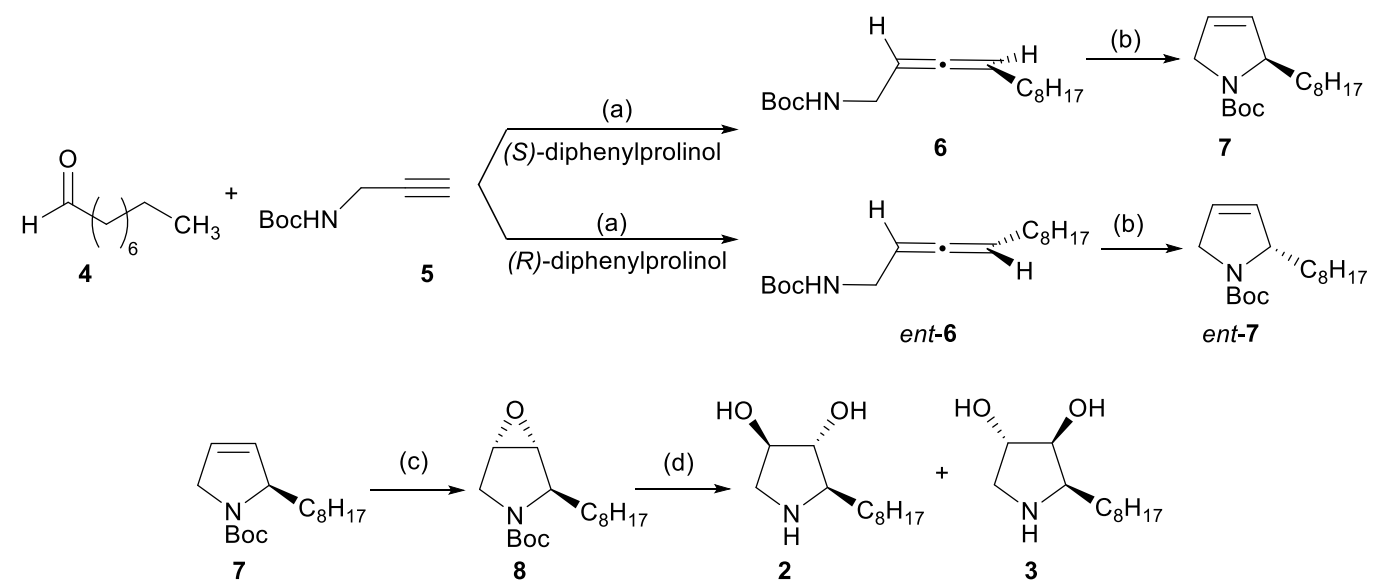

Scheme 1. Reagents and conditions (a) $\mathrm{CuBr}_{2}$, dioxane, $130^{\circ} \mathrm{C}$, overnight (6: $66.5 \%$ yield, $96 \%$ ee; ent-6: $63 \%$ yield, $94 \%$ ee ); (b) AgNO ${ }_{3}$, acetone (7: $98 \%$ yield, $96 \%$ ee; ent-7: $100 \%$ yield, ee not determined); (c) $m$ - $\mathrm{CPBA}_{1} \mathrm{CH}_{2} \mathrm{CL}_{2}$, rt, $48 \mathrm{~h}$, dr 100\% (8: $75 \%$ yield; ent-8: $80 \%$ yield); (d) $\mathrm{H}_{2} \mathrm{SO}_{4}$, dioxane, reflux (2: $50 \%$ yield and 3: $13 \%$ yield; ent-2: $55 \%$ yield ent-3: not isolated) 
The obtained pyrroline proved to be unstable, spontaneously aromatizing to the corresponding pyrrole upon exposure to atmospheric oxygen. So, it was engaged without purification in $m$-CPBA epoxidation to provide epoxypyrrolidine 8 (and ent-8) with $75-80 \%$ yield and $100 \%$ diastereoselectivity. Finally, acidic treatment using diluted $\mathrm{H}_{2} \mathrm{SO}_{4}$ allowed concomitant deprotection of the amino group and the regioand diastereoselective hydrolysis of the epoxide (4:1 diastereoisomeric ratio), an outcome consistent with our previous results. ${ }^{28}$

\section{Evaluation of $\mathbf{2}$ and ent-2 as $\boldsymbol{\beta}$-GCase inhibitors and kinetic analysis}

The $I C_{50}$ values of enantiomers 2 and ent- $\mathbf{2}$ are shown in table 1 and compared to previous data. ${ }^{26} \mathrm{~N}$-Nonyldeoxynojirimycin (NN-DNJ), a potent ASSC, ${ }^{22}$ was also evaluated as a reference compound and an $\mathrm{IC}_{50}$ value of $2.97 \mu \mathrm{M}$ was found in accordance with previous studies. ${ }^{29}$ Remarkably, removal of the hydroxymethyl moiety in $\mathbf{2}$ led to a marked increase in $\beta$-GCase inhibition. Indeed, the latter displayed an $\mathrm{IC}_{50}$ of $0.78 \mu \mathrm{M}$, a value about 10 times lower than the one reported for $\alpha-1-C$-Octyl-DAB $1 .^{26}$ The same detrimental influence of hydroxymethyl on $\beta$-GCase inhibitory was noticed earlier by others. ${ }^{30}$ Moreover, the D-like derivative $\mathbf{2}$ was two orders of magnitude more potent $\beta$-GCase inhibitor than its enantiomer ent-2 than only displayed an $\mathrm{IC}_{50}$ of $59.6 \mu \mathrm{M}$.

Prompted by these promising data, we determined the inhibition constant $\left(K_{i}\right)$ and the mode of inhibition of $\mathbf{2}$ and ent2 by Lineweaver-Burk plots (see ESI). Interestingly, whereas the L-like compound ent-2 behaved as a competitive inhibitor of $\beta$ GCase, its enantiomer $\mathbf{2}$ acted as a non-competitive inhibitor Consequently, one could postulate that recognition of the substrate in the active site is altered upon enzyme conformational modification ensuing the binding of $\mathbf{2}$ to a distinct protein site. This result is in opposition with those obtained by Hirono and coll. who reported a competitive inhibition mode for $\alpha$-1-C-tridecyl-DAB (Ki $0.71 \mu \mathrm{M}) .{ }^{26}$ To substantiate the fact that $\mathbf{2}$ and ent-2 bind at different sites of the protein, the Theorell's graphical method was applied (Figure 2). ${ }^{31,13}$ Competition experiments were performed between NNDNJ and ent-2 showing that both compounds interact with the same binding pocket, thus confirming that ent- $\mathbf{2}$ is a competitive inhibitor. On the other hand, NN-DNJ and compound $\mathbf{2}$ were found to interact with different sites of the protein in accordance with the non-competitive behavior of $\mathbf{2}$.

\begin{tabular}{ccccc}
\multicolumn{7}{l}{ Table 1. Inhibition of $\beta$-GCase } \\
\hline Compound & $\mathrm{IC}_{50}(\mu \mathrm{M})$ & $K i(\mu \mathrm{M})$ & $\begin{array}{c}\text { Inhibition } \\
\text { mode }\end{array}$ \\
\hline $\begin{array}{c}\text { DAB } \\
\text { derivatives }\end{array}$ & $\mathbf{1}$ & $6.20^{\mathrm{a}}$ & - & - \\
\hline LAB & ent-1 & $0.78 \pm 0.14$ & $0.40 \pm 0.09$ & $\begin{array}{c}\text { non- } \\
\text { competitive }\end{array}$ \\
derivatives & ent-2 & $59.60 \pm 5.1$ & $6.87 \pm 1.37$ & competitive \\
& & 7 & & - \\
\hline
\end{tabular}

\footnotetext{
a according to reference $26^{\mathrm{b}} \mathrm{NI}$ : no inhibition (less than $50 \%$ inhibition at $1000 \mu \mathrm{M}$ )
}

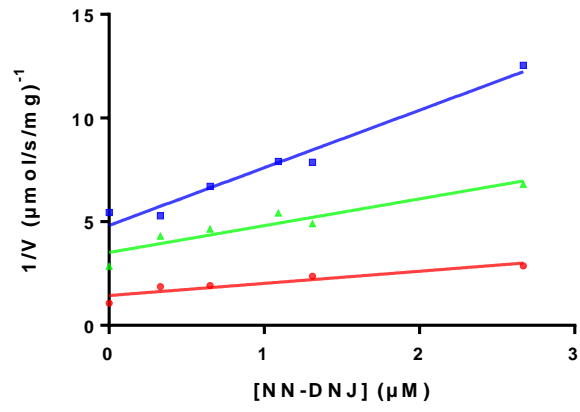

Compound 2

$\rightarrow$ No addition

$\longrightarrow 7.63 \mu \mathrm{M}$

$=3.81 \mu \mathrm{M}$

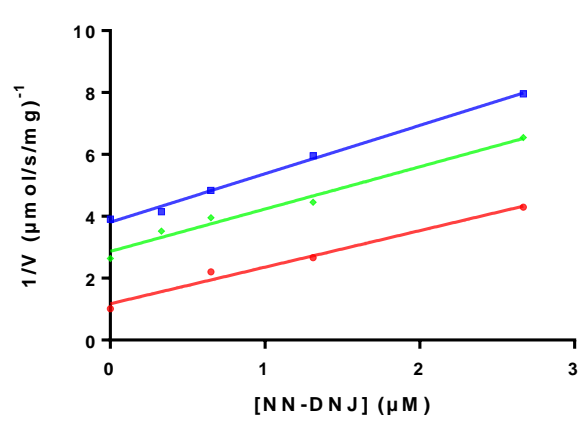

Compound ent-2

$\rightarrow$ No addition

$\rightarrow 21,83 \mu \mathrm{M}$

$\rightarrow 43,06 \mu \mathrm{M}$

Figure 2. Multiple inhibition of $\beta$-GCase by compounds 2 and ent-2. (A) Lack of competition between compound $\mathbf{2}$ and NN-DNJ ; (B) competition between ent-2 and NNDNJ.

\section{Docking studies}

In order to gain insights into the impact of the chirality of $\mathbf{2}$ and ent-2 on their binding mode to $\beta$-GCase, docking studies were performed. Even if kinetic studies had shown a noncompetitive behavior for $\mathbf{2}$ vs. a competitive inhibition for ent2, we compared, in a first approach, the binding of both enantiomers to the $\beta$-GCase active site. From X-ray GCase crystal structures, ${ }^{32-35}$ a conformity pattern was defined gathering the common features of different co-crystallized ligands, i.e. the location of the hydroxyl groups and nitrogen atoms, the orientation of the heterocycles, and the set of key hydrogen-bond interactions (see Experimental section). The crystal structure of $\beta$-GCase in complex with IFG (PDB code 2 NSX) ${ }^{2}$ was submitted to docking protocol P1-OPT allowing protein flexibility ${ }^{34,36}$ and successffully checked against the cocrystallized structures of IFG (from PDB structure, code 2NSX) and NN-DNJ (from PDB structure, code 2V3E) that were used as references. ${ }^{32,34}$

The figure 3 shows the significant poses for compounds ent2 (Figure 3, middle) and 2 (Figure 3, right), highlighting the fluctuations of the alkyl chains among the different poses. The heterocyclic core of compound ent-2 is aligned with those of NN-DNJ and IFG, whereas its nitrogen atom matches with that of IFG. The typical hydrogen-bond interactions are also developped with GLU235, GLU340, TRP179, ASP127 (Figure 4, middle).$^{34}$ In particular, whereas the protonated nitrogen atom is tightly bound to both GLU235 and GLU340, the 1,2-diol 
moiety closely interacts with TRP179 and ASP127. Thus, ent-2 appears to obey all compliance criteria. On the other hand, the heterocycle of $\mathbf{2}$ is found orthogonal to the piperidine plane of both IFG and NN-DNJ in X-ray co-structures while its nitrogen atom matches with that of NN-DNJ (Figure 3, right). As a consequence, the hydrogen-bond with TRP179 is lost and one of the hydroxyl groups now interacts with GLU340, leaving only GLU235 to interact with the protonated nitrogen atom of 2 (Figure 4, right). Overall, these in silico data (see also ESI), indicating that $\mathbf{2}$ would less fit in the active site than its enantiomer, are in accordance with a non-competitive behavior for $\mathbf{2} v$ s. a competitive one for ent-2.

To avoid potential bias due to the high degree of liberty allowed by residue flexibility in P1-OPT protocol, the P2-GPU docking protocol (rigid protein docking, see Experimental section) was used to screen potential interactions at the protein surface. Using P2-GPU protocol, similar docking results were found for compound ent-2, while docking poses of compound $\mathbf{2}$ were exclusively centered in an alternative binding site located near the catalytic cavity (Figure 5) and close to LYS346. Interestingly, this protein region was recently identified as an allosteric site of $\beta$-GCase (PDB code $5 \mathrm{LVX}$ ). ${ }^{12}$ If additional experiments would be necessary to confirm the binding location of $\mathbf{2}$, this data further support the non-competitive behavior of this inhibitor.

\section{Intracellular enhancement of residual enzyme activity in Gaucher fibroblasts}

First, the potential cytotoxicity of pyrrolidines $\mathbf{2}$ and ent-2 was assessed on healthy fibroblasts as well as on N370S homozygous GD fibroblasts (see ESI). Both compounds showed a weak toxicity on the different cell lines (67-89\% viability at 30 $\mu \mathrm{M})$. This result is noteworthy when compared to the high cytotoxicity observed with similar pyrrolidines. ${ }^{36}$

We further tested the PC activity on human fibroblasts incubated for $72 \mathrm{~h}$ with $\mathbf{2}$ and ent-2, and compared it to IFG and NN-DNJ. Two different cell lines, F01pAS and F02pAS, from homozygous GD patients bearing the N370S mutation, were selected. Indeed, intracellular enzymatic enhancement may highly depend on the chosen cell lines. At $30 \mu \mathrm{M}, \mathbf{2}$ and ent-2 displayed a significant increase in $\beta$-GCase activity, of up to 2fold for $\mathbf{2}$ in F01pAS (Figure 6). Reducing the concentration to 3 $\mu \mathrm{M}$ led to a slight decrease in the $\beta$-GCase activity enhancement for ent-2 and virtually no diminition for $\mathbf{2}$, both in F01pAS and F02pAS.
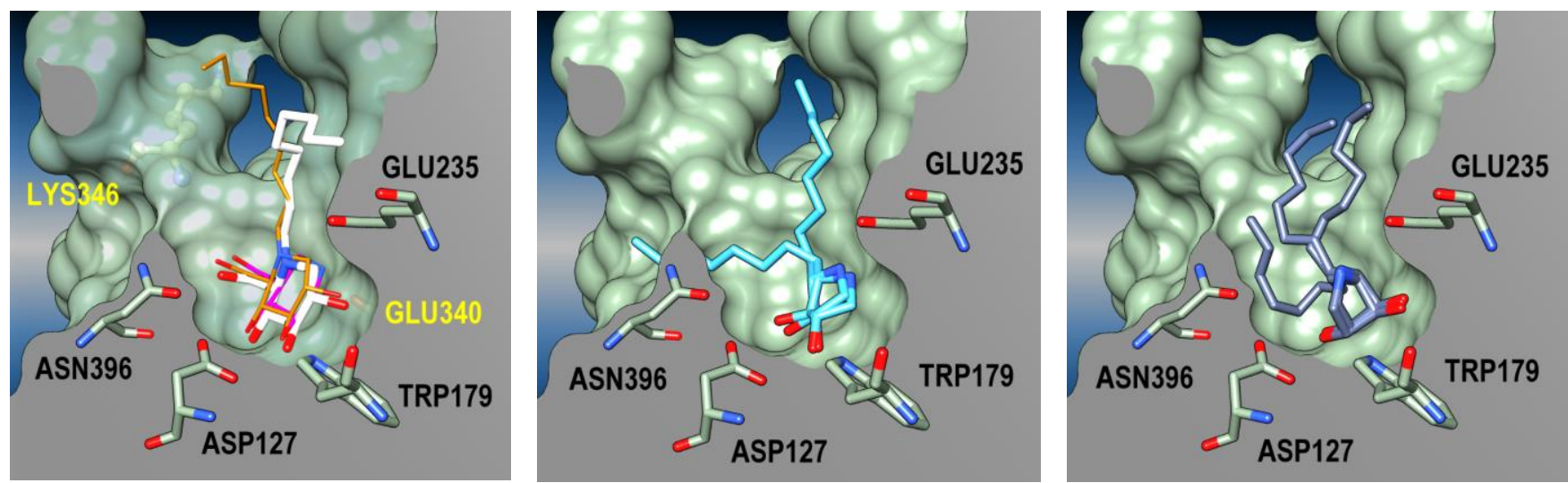

Figure 3. Best poses (P1-OPT docking protocol) of NN-DNJ (white, left), compound ent-2 (cyan, middle) and $\mathbf{2}$ (dark blue, right) in the active site of $\beta$-GCase (PDB code 2 NSX, chain B). Left : IFG (pink) is the co-crystallized ligand (PDB code 2NSX), NN-DNJ (orange) is the co-crystallized ligand (PDB code 2V3E); LYS346 and GLU340 behind the molecular surface or clipping plane. Middle and right : the chain fluctuations are illustrated with the best poses of $\mathbf{2}$ and ent-2 (similar docking scores).
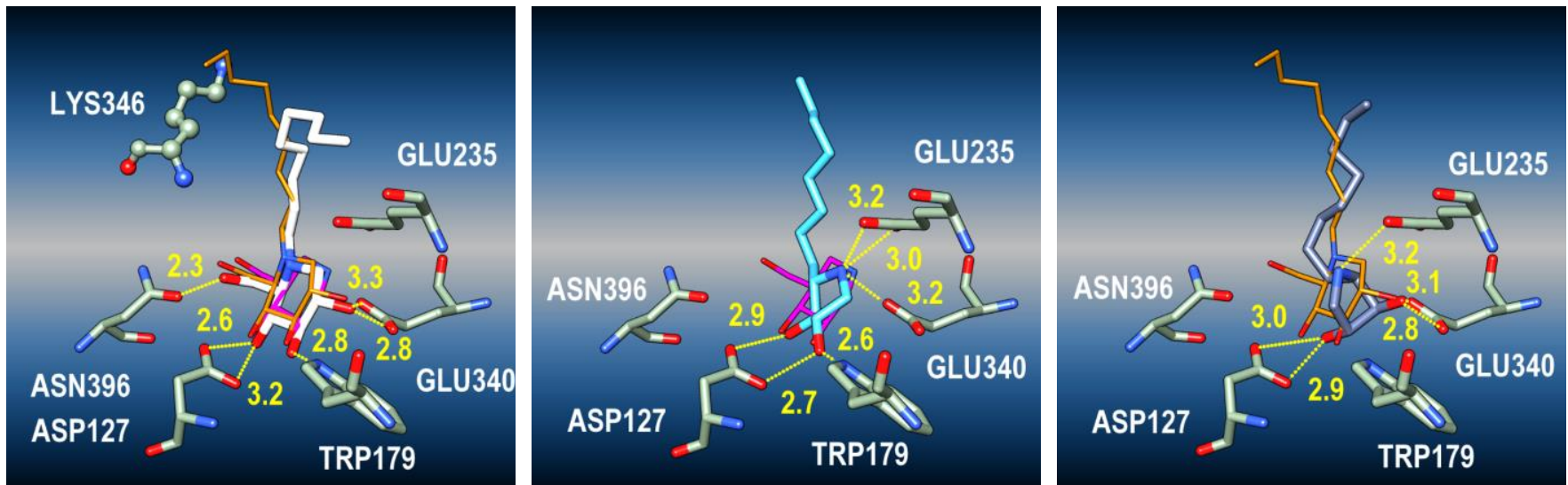

Figure 4. Typical interaction networks of hydrogen bonds, after docking (one pose issued from figure 3 per image) in the case of NN-DNJ (white), compound ent-2 (cyan) and $\mathbf{2}$ (dark blue) relative to the co-crystallized ligands NN-DNJ (orange) and IFG (pink). Distance values (yellow) in ångströms. 


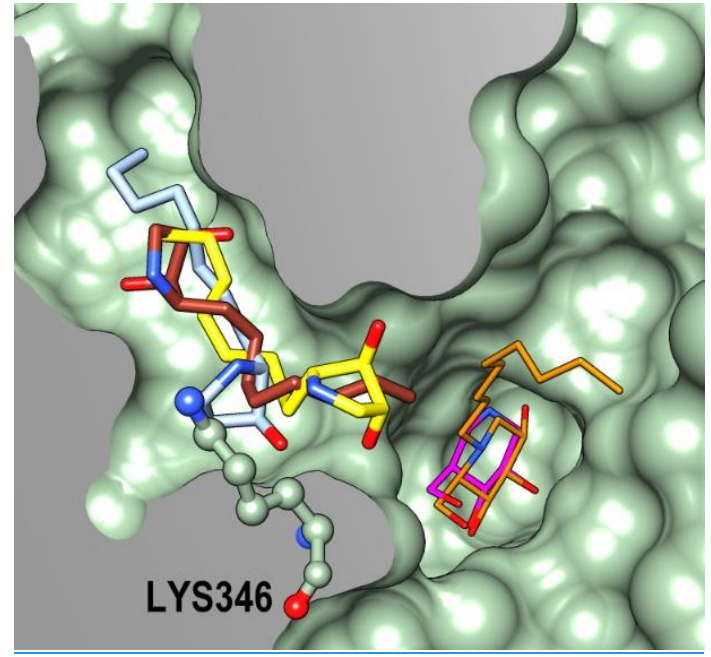

Figure 5. Comparison of NN-DNJ (orange) and IFG (pink) with best poses of $\mathbf{2}$ calculated with the P2-GPU docking protocol. LYS346 residue is displayed with ball and stick representation. Three binding modes of $\mathbf{2}$ with similar docking scores are shown depending of the heterocyclic core location: in front of the active site (yellow), far from the active site (maroon) and an intermediate position (cyan).

Overall, F02pAS proved slightly less responsive. Yet, at both concentrations, the effect of $\mathbf{2}$ revealed comparable to that of NN-DNJ in both cell lines and to that of IFG in F02pAS.

It is remarkable that, compared to what was reported for the $\alpha-1-C$-nonyl analogue 1 of $D A B,{ }^{26}$ the removal of the hydroxymethyl appendage in $\mathbf{2}$ does not seem to alter the chaperoning ability, in agreement with the inhibition and docking data. It is also worth mentioning that, despite of being a poor competitive inhibitor, ent-2 proved to be a significant chaperone. These results shows that inhibitory potency does not necessarily correlate with chaperone activity. Besides it should be noted that potent non-competitive inhibitors such as $\mathbf{2}$ can behave as equally powerful PC as competitive ones.

\section{Conclusion}

The asymmetric synthesis of compounds $\mathbf{2}$ and ent-2 was performed in only four steps with good global yield (ca. 25\%) and high optical purity (>94\%). While the compound ent-2 acted as a poor $\beta$-GCase competitive inhibitor (Ki $6.97 \mu \mathrm{M})$, its enantiomer 2 revealed to be a potent non-competitive inhibitor (Ki $0.40 \mu \mathrm{M})$. Docking studies allowed a better understanding of the protein binding mode of $\mathbf{2}$ and ent-2. The heterocycle of compound ent-2 is tightly aligned with those of NN-DNJ and IFG retaining the main key hydrogen-bond interactions with $\beta$ GCase binding site while compound $\mathbf{2}$ might bind to the recently uncovered allosteric site. Both enantiomers were able to enhance $\beta$-GCase activity in N370S homozygous GD fibroblasts at $3 \mu \mathrm{M}$ and $30 \mu \mathrm{M}$. The non-competitive inhibitor $\mathbf{2}$ behaved as a powerful PC in the two GD cell lines tested with $\beta$-GCase activity enhancement comparable to that of the reference $P C s$, IFG and NN-DNJ. These findings open the way toward the design of two-headed compounds linking enantiomeric competitive and non-competitive inhibitors as previously envisonned by others. ${ }^{37}$
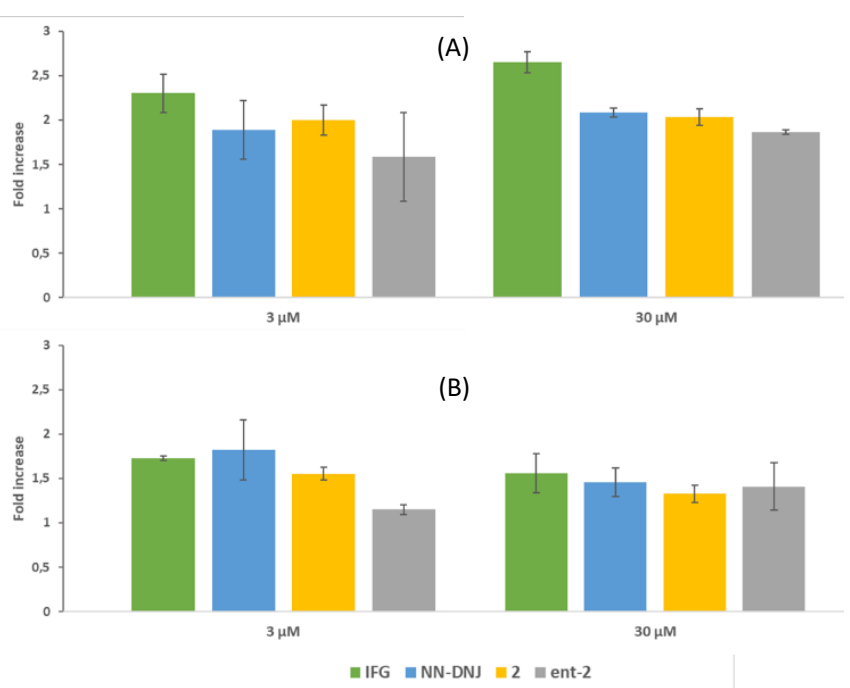

Figure 6. Effect of IFG, NN-DNJ, 2 and ent-2 on lysosomal $\beta$-GCase activity after $72 \mathrm{~h}$ in N370S fibroblasts (A) F01 pAS (B) F02 pAS and compared to untreated cells.

\section{Experimental}

\section{Chemistry}

General methods. Reactions were monitored using Merck silica gel 60 F254 precoated plates. Visualization was accomplished with UV light (at $254 \mathrm{~nm}$ ) and exposure to TLC stains, phosphomolybdic acid or potassium permanganate, followed by heating. FlashColumn chromatography was carried out with SDS 35-70 $\mu \mathrm{m}$ flash silica gel. NMR spectroscopic data were recorded on a Bruker Avance 300, 400 or $500 \mathrm{MHz}$ spectrometer with solvent peaks as reference. Chemical shifts are quoted in parts per million (ppm) relative to residual solvent peak. Mass spectrometry (MS) data were obtained on a ThermoQuest TSQ 7000 spectrometer. High-resolution mass spectra (HRMS) were performed on a ThermoFinnigan MAT $95 \mathrm{XL}$ spectrometer. Anhydrous solvents were obtained by drying prior to use according to standard methods (D.D. Perrin, W.L. Amarego, Purification of Laboratory Chemicals, 3rd Ed., Pergamon Press, 1998).

Preparation of aminoallene 6 and ent-6. To a flame-dried Schlenk tube with a polytetrafluoroethylene plug, $\mathrm{CuBr}_{2}(0.2 \mathrm{eq}), \mathrm{N}$-Bocpropargylamine (1.5 eq), (S)- or ( $R$ )- diphenylprolinol (1 eq) and aldehyde $(1.5 \mathrm{eq})$ in dioxane $(0.3 \mathrm{M})$ were added sequentially under nitrogen atmosphere. The Schlenk tube was then sealed by screwing a polytetrafluoroethylene plug tightly. The reaction was complete after being stirred in an oil bath preheated at 130 ${ }^{\circ} \mathrm{C}$ for 12 hours as monitored by TLC. After cooling to rt, the resulting mixture was diluted with ether and washed with aqueous solution of hydrochloric acid (1 M). The organic layer was separated and the aqueous layer was extracted with diethyl ether twice. The combined organic layer was washed with brine and dried over anhydrous $\mathrm{MgSO}_{4}$. After filtration and evaporation, the residue was purified by chromatography (eluent: petroleum ether/ethyl acetate $=100 / 1$ ) on silica gel to give the desired product. Enantiomeric excess was measured by chiral HPLC (conditions: Column Lux $3 \mu \mathrm{m}$ amylose-1 4.6×100 
$\mathrm{mm}, \mathrm{H}_{2} \mathrm{O} / \mathrm{CH}_{3} \mathrm{OH}=15 / 85,0.6 \mathrm{~mL} \cdot \mathrm{min}^{-1}, \lambda 220 \mathrm{~nm} \mathrm{t}_{\mathrm{R}}(6)=8.241$ $\min , \mathrm{t}_{\mathrm{R}}($ ent-6) $=10.724 \mathrm{~min})$.

(R)-tert-Butyl dodeca-2,3-dien-1-ylcarbamate, compound 6 . colorless oil (910 mg, $66.5 \%$ ). $96 \%$ ee. $[\alpha]_{D}^{20}=-47.33$ (c 0.90 $\left.\mathrm{CHCl}_{3}\right) \cdot R_{\mathrm{f}}($ Petroleum ether/ethyl acetate $=9 / 1)=0.25 .{ }^{1} \mathrm{H}-\mathrm{NMR}$ (300 MHz, $\left.\mathrm{CDCl}_{3}\right) \delta 5.30-5.10(\mathrm{~m}, 2 \mathrm{H}, \mathrm{H} 2$ and H3), 4.59 (bs, $1 \mathrm{H}$, $\mathrm{NH}), 3.68(\mathrm{~s}, 2 \mathrm{H}, \mathrm{H} 1), 2.05-1.93(\mathrm{~m}, 2 \mathrm{H}, \mathrm{H} 5), 1.51-1.18(\mathrm{~m}$, $12 \mathrm{H}, \mathrm{H} 6-\mathrm{H} 11), 1.44$ (s, 9H, $\left.\mathrm{CH}_{3} \mathrm{Boc}\right), 0.97-0.77$ (t, J $6.8 \mathrm{~Hz}, 3 \mathrm{H}$, H12) ppm. Data in accordance with reference 27.

(S)-tert-Butyl dodeca-2,3-dien-1-ylcarbamate, compound ent6. Colorless oil (311 mg, $63 \%$ ). $94 \%$ ee. $[\alpha]_{D}^{20}=+47.15$ (c 1.21, $\mathrm{CHCl}_{3}$ ). Spectroscopic data identical to compound 6 .

Preparation of pyrrolines 7 and ent-7. To a solution of aminoallene 6 or ent- $6(1 \mathrm{eq})$ in acetone $(0.3 \mathrm{M}), \mathrm{AgNO}_{3}(0.2 \mathrm{eq})$ was added. The reaction mixture was stirred in the dark for 48 hours. The reaction mixture was diluted with ethyl acetate and filtered through Celite, dried over anhydrous $\mathrm{MgSO}_{4}$ and evaporated to give the desired product. Enantiomeric excess was measured by chiral HPLC (conditions: Column Lux $3 \mu \mathrm{m}$ amylose-1 4.6x100 mm, $\mathrm{H}_{2} \mathrm{O} / \mathrm{CH}_{3} \mathrm{OH}=15 / 85,0.6 \mathrm{~mL} \cdot \mathrm{min}^{-1}, \lambda$ $220 \mathrm{~nm} \mathrm{t}_{\mathrm{R}}(7)=6.111 \mathrm{~min}, \mathrm{t}_{\mathrm{R}}($ ent-7) $=5.631 \mathrm{~min})$.

(R)-tert-Butyl 2-octyl-2,5-dihydro-1H-pyrrole-1-carboxylate, compound 7. colorless oil ( $899 \mathrm{mg}, 98 \%$ ). $96 \%$ ee. $R_{\mathrm{f}}$ (Petroleum ether/ethyl acetate $=9 / 1)=0.25 .{ }^{1} \mathrm{H}-\mathrm{NMR}\left(300 \mathrm{MHz} \mathrm{CDCl}_{3}\right) \delta$ $5.82-5.63(\mathrm{~m}, 2 \mathrm{H}, \mathrm{H} 2$ and $\mathrm{H} 3), 4.49(\mathrm{~m}, 1 \mathrm{H}, \mathrm{H} 1), 4.27-3.90(\mathrm{~m}$, $2 \mathrm{H}, \mathrm{H} 4), 1.89-1.53(\mathrm{~m}, 2 \mathrm{H}, \mathrm{H} 5), 1.47\left(\mathrm{~s}, 9 \mathrm{H}, \mathrm{CH}_{3} \mathrm{Boc}\right), 1.36-$ $1.13(\mathrm{~m}, 12 \mathrm{H}, \mathrm{H} 6-\mathrm{H} 11), 0.87(\mathrm{t}, J 6.5 \mathrm{~Hz}, 3 \mathrm{H}, \mathrm{H} 12) \mathrm{ppm} .{ }^{13} \mathrm{C}-\mathrm{NMR}$ $\left(75 \mathrm{MHz}, \mathrm{CDCl}_{3}\right) \delta 154.3$ (C=O Boc rotamer 1), 154.1 (C=O Boc, rotamer 2 ), 130.3 (C2 or $\mathrm{C} 3$, rotamer 2 ), 130.2 (C2 or $\mathrm{C} 3$, rotamer 1 ), 125.0 (C2 or C3, rotamer 1 ), 124.8 (C2 or C3, rotamer 2), 79.3 (Cq Boc rotamers 1 and 2 ), 64.2 (C4 rotamer 2 ), 64.0 (C4 rotamer 1$), 53.8$ (C1 rotamer 2 ), 53.6 (C1 rotamer 1 ), $28.5\left(\mathrm{CH}_{3}\right.$ Boc rotamers 1 and 2), 14.1 (C12), 34.0, 33.5, 31.8, 29.7, 29.2, 24.4, 22.7 (C5-C11 rotamers 1 and 2) ppm.

(S)-tert-Butyl 2-octyl-2,5-dihydro-1H-pyrrole-1-carboxylate, compound ent-7. colorless oil (148 mg, $100 \%$ ). Spectroscopic data identical to compound $\mathbf{7}$.

Preparation of epoxypyrrolidines 8 and ent-8. $m$-CPBA ( 2 eq) was dissolved in dry $\mathrm{CH}_{2} \mathrm{Cl}_{2}$ over anhydrous $\mathrm{MgSO}_{4}$ and then added dropwise to the solution of pyrroline 7 or ent-7 (1 eq) in dry $\mathrm{CH}_{2} \mathrm{Cl}_{2}$ under nitrogen atmosphere. The reaction mixture was stirred at $\mathrm{rt}$ for 48 hours as monitored by TLC. The resulting mixture was washed with an aqueous solution of $\mathrm{NaOH}(10 \%$ $\mathrm{w} / \mathrm{v})$. Organic layer was separated, dried over anhydrous $\mathrm{MgSO}_{4}$ and evaporated. The residue was then purified by chromatography (eluent: petroleum ether/ethyl acetate = $85 / 15$ ) on silica gel to give the desired product.

(1R,5S)-tert-Butyl 2-octyl-6-oxa-3-azabicyclo[3.1.0]hexane-3carboxylate, compound 8 . White solid $(370.3 \mathrm{mg}, 75 \%) .[\alpha]_{D}^{20}=$ -48.67 (c 1.13, $\mathrm{CHCl}_{3}$ ). $R_{\mathrm{f}}$ (Petroleum ether/ ethyl acetate $=$ $85 / 15)=0.1 .{ }^{1} \mathrm{H}-\mathrm{NMR}\left(300 \mathrm{MHz}, \mathrm{CDCl}_{3}\right) \delta 4.05$ (dd, J 7.5 Hz, 4.9 $\mathrm{Hz}, 1 \mathrm{H}, \mathrm{H} 1$ rotamer 2$), 3.96(\mathrm{t}, J 6.1 \mathrm{~Hz}, 1 \mathrm{H}, \mathrm{H} 1$ rotamer 1$), 3.88$ (d, J $12.9 \mathrm{~Hz}, 1 \mathrm{H}, \mathrm{H} 4$ rotamer 1), $3.78(\mathrm{~d}, J 12.9 \mathrm{~Hz}, 1 \mathrm{H}, \mathrm{H} 4$ rotamer 2$), 3.60(\mathrm{dd}, J 3.1 \mathrm{~Hz}, 1.1 \mathrm{~Hz}, 1 \mathrm{H}, \mathrm{H} 3$ rotamer 1$), 3.58$ (dd, J $3.0 \mathrm{~Hz}, 1.1 \mathrm{~Hz}, 1 \mathrm{H}, \mathrm{H} 3$ rotamer 2), 3.45 (d, J $3.2 \mathrm{~Hz}, 1 \mathrm{H}, \mathrm{H} 2$ rotamer 2), 3.43 (d, J $3.1 \mathrm{~Hz}, 1 \mathrm{H}, \mathrm{H} 2$ rotamer 1 ), 3.24 (dd, J 12.9, $1.1 \mathrm{~Hz}, 1 \mathrm{H}, \mathrm{H} 4$ rotamers 1 and 2), $1.74-1.11(\mathrm{~m}, 14 \mathrm{H}, \mathrm{H} 5-\mathrm{H} 11$ rotamers 1 and 2), $1.40(\mathrm{~s}, 9 \mathrm{H}$, Boc rotamer 1$), 1.39(\mathrm{~s}, 9 \mathrm{H}$, Boc rotamer 2$), 0.93-0.79(\mathrm{~m}, 3 \mathrm{H}, \mathrm{H} 12$ rotamers 1 and 2$) \mathrm{ppm}$. Ratio rotamer $1 /$ rotamer $2=3 / 2 .{ }^{13} \mathrm{C}-\mathrm{NMR}\left(75 \mathrm{MHz}, \mathrm{CDCl}_{3}\right) \delta$ 155.1 (C=O Boc rotamer 2), 155.0 ( $\mathrm{C}=\mathrm{O}$ Boc rotamer 1 ), 79.8 ( $\mathrm{Cq}$ Boc rotamer 1 ), 79.6 (Cq Boc rotamer 2 ), 58.6 (C3 rotamer 1 ), 58.1 (C3 rotamer 2 ), 57.9 (C4 rotamer 1 ), 57.6 (C4 rotamer 2 ), 54.9 (C2 rotamer 2 ), 54.3 (C2 rotamer 1 ), 47.1 (C1 rotamer 2 ), 46.5 (C1 rotamer 1), 31.9, 31.2, 29.8, 29.7, 29.5, 29.2 (C5 - C12 rotamers 1 and 2), $28.5\left(\mathrm{CH}_{3}\right.$ Boc rotamers 1 and 2), 25.6, 22.7 (C5 - C12 rotamers 1 and 2), 14.1 (C12 rotamers 1 and 2) ppm. HRMS (IC, $\mathrm{NH}_{3}$ ) calcd for $\mathrm{C}_{17} \mathrm{H}_{31} \mathrm{NO}_{3}\left(\mathrm{MH}^{+}\right)$297.2304, found 297.2299.

(1S,5R)-tert-Butyl 2-octyl-6-oxa-3-azabicyclo[3.1.0]hexane-3carboxylate, compound ent-8. White solid $(238 \mathrm{mg}$, $80 \%$ ). $[\alpha]_{D}^{20}=+43.36$ (c 1.09, $\mathrm{CHCl}_{3}$ ) Spectroscopic data identical to compound 8.

Preparation of pyrrolidines $\mathbf{2}$ and ent-2. To a solution of epoxide (1 eq) in dioxane $\left(0.15 \mathrm{M}\right.$ ), aqueous solution of $\mathrm{H}_{2} \mathrm{SO}_{4}$ (8 eq, 3 $\mathrm{M})$ was added dropwise. The reaction was refluxed for 4 hours. After cooling to $\mathrm{rt}$, the reaction mixture was neutralized with an aqueous solution of $\mathrm{NaOH}(3 \mathrm{M})$, evaporated and then diluted with ethyl acetate, dried over anhydrous $\mathrm{MgSO}_{4}$ and evaporated.

Compound 2. slightly yellow solid (39 mg, 50\%). $[\alpha]_{D}^{20}=-1.03$ (c $\left.0.98, \mathrm{CH}_{3} \mathrm{OH}\right) . R_{\mathrm{f}}\left(\mathrm{CH}_{3} \mathrm{OH} / \mathrm{C}_{2} \mathrm{H}_{5} \mathrm{OH} / \mathrm{NH}_{4} \mathrm{OH} / \mathrm{CH}_{2} \mathrm{Cl}_{2}=5 / 7 / 3 / 85\right)=$ 0.3. ${ }^{1} \mathrm{H}-\mathrm{NMR}(300 \mathrm{MHz}, \mathrm{MeOD}) \delta 4.02$ (dt, J $5.3 \mathrm{~Hz}, 2.8 \mathrm{~Hz}, 1 \mathrm{H}$, H3), 3.63 (ddd, J $5.1 \mathrm{~Hz}, 2.8 \mathrm{~Hz}, 1.0 \mathrm{~Hz}, 1 \mathrm{H}, \mathrm{H} 2$ ), 3.03 (dd, J 12.1 $\mathrm{Hz}, 5.0 \mathrm{~Hz}, 1 \mathrm{H}, \mathrm{H} 4), 2.92-2.81\left(\mathrm{~m}, 1 \mathrm{H}, \mathrm{H} 4{ }^{\circ}\right), 2.81-2.71(\mathrm{~m}, 1 \mathrm{H}$, $\mathrm{H} 1), 1.81-1.21(\mathrm{~m}, 14 \mathrm{H}, \mathrm{H} 5-\mathrm{H} 11), 1.02-0.85$ (m, 3H, H12) ppm. ${ }^{13} \mathrm{C}-\mathrm{NMR}$ (75 MHz, MeOD) $\delta 82.8$ (C2), 78.1 (C3), 65.7 (C1), 51.6 (C4), 33.6, 31.7, 29.4, 29.3, 29.0, 26.8, 22.3 (C5 - C11), 13.0 (C12) ppm. HR-MS (ESI) $\mathrm{C}_{12} \mathrm{H}_{26} \mathrm{NO}_{2}$ calc 216.1964. Found. 216.1978. Compound ent-2. slightly yellow solid ( $25 \mathrm{mg}, 55 \%$ ). $[\boldsymbol{\alpha}]_{D}^{20}=+1.30$ (c 1.05, $\left.\mathrm{CH}_{3} \mathrm{OH}\right)$. Spectroscopic data identical to compound 14.

Compound 3. slightly yellow solid $(9 \mathrm{mg}, 13 \%) R_{\mathrm{f}}$ $\left(\mathrm{CH}_{3} \mathrm{OH} / \mathrm{C}_{2} \mathrm{H}_{5} \mathrm{OH} / \mathrm{NH}_{4} \mathrm{OH} / \mathrm{CH}_{2} \mathrm{Cl}_{2}=5 / 7 / 3 / 85\right)=0.25 .{ }^{1} \mathrm{H}-\mathrm{NMR}$ (300 MHz, MeOD) $\delta 4.08$ (ddd, J $5.5 \mathrm{~Hz}, 2.0 \mathrm{~Hz}, 1.2 \mathrm{~Hz}, 1 \mathrm{H}, \mathrm{H} 3$ ), 3.83 (dd, J $3.3 \mathrm{~Hz}, 1.1 \mathrm{~Hz}, 1 \mathrm{H}, \mathrm{H} 2$ ), 3.36 (dd, J $12.5 \mathrm{~Hz}, 5.8 \mathrm{~Hz}, 1 \mathrm{H}$, H4), 3.08 (td, J $7.1 \mathrm{~Hz}, 3.2 \mathrm{~Hz}, 1 \mathrm{H}, \mathrm{H} 1$ ), 2.66 (dd, J $12.5 \mathrm{~Hz}, 2.0$ $\mathrm{Hz}, 1 \mathrm{H}, \mathrm{H} 4), 1.71-1.21(\mathrm{~m}, 14 \mathrm{H}), 0.89(\mathrm{t}, J 6.75 \mathrm{~Hz}, 3 \mathrm{H}, \mathrm{H} 12)$ ppm. ${ }^{13} \mathrm{C}-\mathrm{NMR}$ (75 MHz, MeOD) $\delta 77.2$ (C3), 77.1 (C2), 61.0 (C1), 51.9 (C4), 31.6, 29.6, 29.3, 29.1, 27.8, 27.0, 22.4 (C5 - C11), 13.1 (C12) ppm. HRMS (DCl, $\left.\mathrm{CH}_{4}\right)$ calcd for $\mathrm{C}_{12} \mathrm{H}_{26} \mathrm{NO}_{2}\left(\mathrm{MH}^{+}\right)$ 216.1964, found 216.1956. Compound ent-3 was not isolated.

\section{Inhibition assays on recombinant $\beta$-GCase}


Recombinant Human $\beta$-GCase/GBA (7410- GH), purchased from $R \& D$ was used in the inhibition studies. The used substrate 4methylumbelliferyl- $\beta$-D-glucopyranoside was purchased by Sigma-Aldrich. $\beta$-GCase activity was determined with 4methylumbelliferyl- $\beta$-D-glucopyranoside as reported in previously. ${ }^{38}$ Briefly, enzyme solutions $(25 \mu \mathrm{L}$ from a stock solution containing $0.6 \mu \mathrm{g} / \mathrm{mL})$ in the presence of $0.25 \%(\mathrm{w} / \mathrm{v})$ sodium taurocholate and $0.1 \%(\mathrm{v} / \mathrm{v})$ Triton X-100 in Mcllvaine buffer ( $100 \mathrm{mM}$ sodium citrate and $200 \mathrm{mM}$ sodium phosphate buffer, $\mathrm{pH} \mathrm{5.2)}$ were incubated at $37^{\circ} \mathrm{C}$ without (control) or with inhibitor at a final volume of $50 \mu \mathrm{L}$ for $30 \mathrm{~min}$. After addition of $25 \mu \mathrm{L}$ 4-methylumbelliferyl- $\beta$-D-glucopyranoside $(7.2 \mathrm{mM}$, Mcllvaine buffer $\mathrm{pH} 5.2$ ), the samples were incubated at $37^{\circ} \mathrm{C}$ for $10 \mathrm{~min}$. Enzymatic reactions were stopped by the addition of aliquots $(100 \mu \mathrm{L})$ of Glycine/ $\mathrm{NaOH}$ buffer $(100 \mathrm{mM}, \mathrm{pH} 10.6)$. The amount of 4-methylumbelliferone formed was determined with a FLUOstar microplate reader (BMG Labtech) at $355 \mathrm{~nm}$ (excitation) and $460 \mathrm{~nm}$ (emission).

\section{Docking studies}

Molecular graphics were performed with the UCSF Chimera package. ${ }^{39}$ Chimera is developed by the Ressource for Biocomputing, Visualization, and Informatics at the University of California, San Francisco (supported by the NIGMS P41GM103311). The protein structures used in this paper were downloaded from the RCSB Protein Database 40 and were structurally aligned with structure $10 \mathrm{GS}^{41}$ (chain A) set as reference and using UCSF Chimera/Matchmaker ${ }^{42}$ program. The protein structures, were prepared (structure checks, rotamers, hydrogenation, splitting of chains) using Biovia (www.3dsbiovia.com) Discovery Studio Visualizer 2016 (DSV) and UCSF Chimera. The new compounds were sketched using ChemAxon Marvin 16, (www.chemaxon.com). All ligands were checked (hybridization, hydrogenation, some geometry optimizations, 3D sketching) and merged in SDF libraries using DSV. The structurally aligned $\beta-G C a s e$ structures were clustered as described in previous paper. ${ }^{43}$ For this study, we retained the cluster described by 2NSX that is the case of an opened structure, in which the fluctuation of LYS346 let open a surface channel near binding cavity. Molecular modeling studies ${ }^{44}$ were carried with Molegro Virtual Docker 6 software (www.clcbio.com) using the B chain of structure 2NSX (2NSXb) as target. ${ }^{34} \mathrm{~A}$ search space volume of $15 \AA$ radius centered in the binding pocket was used, the ligands were set flexible during the docking, and two different docking protocols were used.

The protocol P1-OPT is based on flexible docking at protein level (softened potentials during docking phase) and Moldock optimizer used as searching algorithm. According to structural study, 23 residues were defined as flexible during the docking: ALA238, ASN234, ASN396, ASP127, ASP283, CYS342, GLN247, GLN284, GLU235, GLU340, LEU241, LEU314, LYS346, PHE128, PHE246, PHE347, PHE397, SER345, TRP179, TRP381, TYR244, TYR313 and VAL398. Docking process uses 10000 iteration steps, other parameters let as default, and returns 20 independent runs. Final minimization (per run) was parameterized using 4000 steps for lateral chains and protein backbone; other parameters were let with default values. No water molecules were taken in account in the study. MolDock and Rerank ${ }^{45}$ scores were calculated post-docking and postminimization.

The protocol P2-GPU is based on rigid docking at protein level and a GPU (Nvidia Tesla CUDA hardware, www.nvidia.com) screening algorithm. Docking process uses the MolDock function (Moldock [grid] with a resolution of $0.2 \AA$ ) for scoring and CUDA optimizer (MVD, 10000 iteration steps, other parameters let as default, and returns 40 independent runs. Post-docking, all the poses were re-ranked using MolDock and Rerank scoring systems (without a post-minimization step).

The two protocols use templates (pharmacophoric model) scoring (similarity score) with a grid resolution of $0.3 \AA$ and a strength of 1000 . The definition of templates was based on aligned protein structures in the same reference space. The conformations and positions of co-crystallized $\beta$-GCase ligands (NBV, IFG, NN-DNJ, BTB, MT5, LGS, 3RI, 3RK) along different structures, showed clearly a lot of tridimensional similarities (atom superposition). This is particularly the case for iminosugar compounds that share similar positions of primary or secondary hydroxy groups. This information was derived to define templates, based on spheres centered in the mean position of similar atoms (such as hydrogen donor or acceptor) found in aligned ligands. Using these structural data, 4 similarity groups (using spheres of $1.8 \AA \AA$ radius) were defined: (i) a steric group of 10 atoms (strength $=0.5$ ) and 3 groups (strength $=1$ ); (ii) a hydrogen donor group of 4 atoms; (iii) a hydrogen acceptor group of 5 atoms; and (iv) a ring atom group of 5 atoms. The cyclic nitrogen atom of some ligands was not included in the template definition, because the position in ring is different for some ligands (i.e. IFG and NN-DNJ).

In order to provide significance of similar conformations (if they occur) the two protocols were checked to avoid biases in calculations (i.e. related to the template strength). Particularly, the aliphatic chain was able to sample the binding cavity along different poses, and docked conformations outside cavity were possible. Under these conditions, reproduction of crystallographic conformations was reached with best RMSDs associated to best combination of MolDock/Rerank scores, such as $0.39 \AA$ for NBV, $0.43 \AA$ for IFG, $1.67 \AA$ for NN-DNG (protocol $\mathrm{P} 1-\mathrm{OPT})$. The results show an accurate reproduction of polar heads associated to the typical network of hydrogen bond involving residues ASN396, ASP127, TRP179, TRP181, GLU340 (case of NN-DNJ) and a fluctuation of aliphatic chain including, at least, a trajectory near from the one found in crystallographic ligand.

The clustering parameters (RMSD threshold $1.5 \AA$, other parameters let as default) were the same for P1-OPT and P2GPU protocols. The same post-docking filtering protocol was used for the two protocols and included a careful inspection of 
all poses. Firstly, the three best poses for MolDock and Rerank scores were selected. The parameter's set used in this study was able to give robust calculations: these best poses were mostly i) strong (ability for a given pose to be, at once, the best value for each score) and ii) conform (ability to reproduce the typical hydrogen bond network found in PDB structures). In the case of this binding site/compounds, the fluctuation of aliphatic chains not impacted notably on these best scores values, so we didn't report scores. Then, two of three significant poses (including fluctuations) were retained as significant poses and reported in results (Figure 3 ) before we use the one, in which the trajectory of aliphatic chain is similar to the counterpart of NN-DNJ (in 2V3E PDB entry).

\section{Assay of $\beta$-GCase Activity on human fibroblasts}

Cultured primary skin fibroblasts from control individuals and patients affected with Gaucher disease (carrying the N370S mutation) were obtained from the Laboratoire de Biochimie Métabolique, CRB, IFB, CHU Toulouse, France and CBC Biotec biobank BB-0033-00046 (3809 F01 and 1541 F02 cell lines), Hospices Civils de Lyon, France. Cells were immortalized after tranfection with a plasmid encoding the SV40 large T antigen. Cells were routinely cultured in DMEM medium supplemented with $10 \%$ inactivated foetal calf serum. Cells were harvested and pelleted. Cell lysates were prepared in $0.2 \%$ Triton X100 by brief sonication. $\beta$-GCase enzyme activity was determined on cell lysates in sodium acetate buffer $\mathrm{pH} 5.6$ using 4methylumbelliferyl- $\beta$-D-glucopyranoside (Sigma-Aldrich, St. louis, MO, USA) as substrate.

\section{Conflicts of interest}

There are no conflicts to declare.

\section{Acknowledgements}

This research was funded by the association 'Vaincre les Maladies Lysosomales'. We thank Université Paul Sabatier for financial support and PhD grant to M.L.T.

\section{Notes and references}

¥ Of note, the formation of such side product, likely resulting from the chiral inductor decomposition, is not explained nor mentioned in the mechanism proposed by $\mathrm{Ma}$ and coll. in reference 27 .

1 J. Stirnemann, N. Belmatoug, F. Camou, C. Serratrice, R. Froissart, C. Caillaud, T. Levade, L. Astudillo, J. Serratrice, A. Brassier, C. Rose, T. Billette de Villemeur and M. Berger, Int. J. Mol. Sci., 2017, 18, 441.

2 A. Dandana, S. Ben Khelifa, H. Chahed, A. Miled and S. Ferchichi, Pathobiology, 2016, 83, 13-23.

3 M. Beck, Dev. Med. Child Neurol., 2018, 60, 13-18.

4 J. J. Miller, A. J. Kanack and N. M. Dahms, Biochim. Biophys. Acta - Gen. Subj., 2019, 1864, 129437.
Y.-X. Tao and P. M. Conn, Physiol. Rev., 2018, 98, 697-725. D. M. Pereira, P. Valentão and P. B. Andrade, Chem. Sci., 2018, 9, 1740-1752.

O. Jung, S. Patnaik, J. Marugan, E. Sidransky and W. Westbroek, Expert Rev. Proteomics, 2016, 13, 1-9.

A. Narita, K. Shirai, S. Itamura, A. Matsuda, A. Ishihara, K. Matsushita, C. Fukuda, N. Kubota, R. Takayama, H. Shigematsu, A. Hayashi, T. Kumada, K. Yuge, Y. Watanabe, S. Kosugi, H. Nishida, Y. Kimura, Y. Endo, K. Higaki, E. Nanba, Y. Nishimura, A. Tamasaki, M. Togawa, Y. Saito, Y. Maegaki, K. Ohno and Y. Suzuki, Ann. Clin. Transl. Neurol., 2016, 3, 200215.

S. Rogers, S. Patnaik, F. Schoenen, W. Zheng, J. Choi, O. Motabar, N. Southall, W. Westbroek, E. Goldin, E. Sidransky, W. Leister, J. J. Marugan and J. Aubé, Discovery, SAR, and Biological Evaluation of Non-inhibitory Chaperones of Glucocerebrosidase, 2010.

J. R. Mazzulli, F. Zunke, T. Tsunemi, N. J. Toker, S. Jeon, L. F. Burbulla, S. Patnaik, E. Sidransky, J. J. Marugan, C. M. Sue and D. Krainc, J. Neurosci., 2016, 36, 7693-7706.

M. L. Tran, Y. Génisson, S. Ballereau and C. Dehoux, Molecules, 2020, 25, 3145.

J. Zheng, L. Chen, O. S. Skinner, D. Ysselstein, J. Remis, P. Lansbury, R. Skerlj, M. Mrosek, U. Heunisch, S. Krapp, J. Charrow, M. Schwake, N. L. Kelleher, R. B. Silverman and D. Krainc, J. Am. Chem. Soc., 2018, 140, 5914-5924.

N. Asano, K. Ikeda, L. Yu, A. Kato, K. Takebayashi, I. Adachi, I. Kato, H. Ouchi, H. Takahata and G. W. J. Fleet, Tetrahedron: Asymmetry, 2005, 16, 223-229.

C. Y. Yu, N. Asano, K. Ikeda, M. X. Wang, T. D. Butters, M. R. Wormald, R. A. Dwek, A. L. Winters, R. J. Nash and G. W. J. Fleet, Chem. Commun., 2004, 10, 1936-1937.

F. P. da Cruz, S. Newberry, S. F. Jenkinson, M. R. Wormald, T. D. Butters, D. S. Alonzi, S. Nakagawa, F. Becq, C. Norez, R. J. Nash, A. Kato and G. W. J. Fleet, Tetrahedron Lett., 2011, 52, 219-223.

Y. Minami, C. Kuriyama, K. Ikeda, A. Kato, K. Takebayashi, I. Adachi, G. W. J. Fleet, A. Kettawan, T. Okamoto and N. Asano, Bioorg. Med. Chem., 2008, 16, 2734-2740.

S. F. Jenkinson, G. W. J. Fleet, R. J. Nash, Y. Koike, I. Adachi, A. Yoshihara, K. Morimoto, K. Izumori and A. Kato, Org. Lett., 2011, 13, 4064-4067.

J. S. S. Rountree, T. D. Butters, M. R. Wormald, S. D. Boomkamp, R. A. Dwek, N. Asano, K. Ikeda, E. L. Evinson, R. J. Nash and G. W. J. Fleet, ChemMedChem, 2009, 4, 378392.

D. D'Alonzo, M. De Fenza, C. Porto, R. lacono, M. Huebecker, B. Cobucci-Ponzano, D. A. Priestman, F. Platt, G. Parenti, M. Moracci, G. Palumbo and A. Guaragna, J. Med. Chem., 2017, 60, 9462-9469.

C. Kuriyama, O. Kamiyama, K. Ikeda, F. Sanae, A. Kato, I. Adachi, T. Imahori, H. Takahata, T. Okamoto and N. Asano, Bioorg. Med. Chem., 2008, 16, 7330-7336.

J. Serra-Vinardell, L. Díaz, J. Casas, D. Grinberg, L. Vilageliu, H. Michelakakis, I. Mavridou, J. M. F. G. Aerts, C. Decroocq, P. Compain and A. Delgado, ChemMedChem, 2014, 9, 17441754. 
A. R. Sawkar, W.-C. Cheng, E. Beutler, C. Wong, W. E. Balch and J. W. Kelly, Proc. Natl. Acad. Sci., 2002, 99, 1542815433.

L. Yu, K. Ikeda, A. Kato, I. Adachi, G. Godin, P. Compain, O. Martin and N. Asano, Bioorg. Med. Chem., 2006, 14, 77367744.

P. Compain, O. R. Martin, C. Boucheron, G. Godin, L. Yu, K. Ikeda and N. Asano, ChemBioChem, 2006, 7, 1356-1359.

F. Oulaïdi, S. Front-Deschamps, E. Gallienne, E. Lesellier, K. Ikeda, N. Asano, P. Compain and O. R. Martin, ChemMedChem, 2011, 6, 353-361.

A. Kato, I. Nakagome, K. Sato, A. Yamamoto, I. Adachi, R. J. Nash, G. W. J. Fleet, Y. Natori, Y. Watanabe, T. Imahori, Y. Yoshimura, H. Takahata and S. Hirono, Org. Biomol. Chem., 2016, 14, 1039-1048.

X. Tang, X. Huang, T. Cao, Y. Han, X. Jiang, W. Lin, Y. Tang, J. Zhang, Q. Yu, C. Fu and S. Ma, Org. Chem. Front., 2015, 2, 688-691.

A. Rives, Y. Génisson, V. Faugeroux, C. Zedde, C. Lepetit, R. Chauvin, N. Saffon, N. Andrieu-Abadie, S. Colié, T. Levade and M. Baltas, Eur. J. Org. Chem., 2009, 2009, 2474-2489.

A. Sevšek, J. Sastre Toraño, L. Quarles Van Ufford, E. E. Moret, R. J. Pieters and N. I. Martin, Medchemcomm, 2017, 8, 2050-2054

M. Martínez-Bailén, A. T. Carmona, A. C. Patterson-Orazem, R. L. Lieberman, D. Ide, M. Kubo, A. Kato, I. Robina and A. J. Moreno-Vargas, Bioorg. Chem., 2019, 86, 652-664.

H. Theorell and T. Yonetani, Arch. Biochem. Biophys., 1964, 106, 252-258.

B. Brumshtein, H. M. Greenblatt, D. Butters, Y. Shaaltiel, D. Aviezer, I. Silman, A. H. Futerman, L. Sussman, T. D. Butters, Y. Shaaltiel, D. Aviezer, I. Silman, A. H. Futerman and J. L. Sussman, J. Biol. Chem., 2007, 282, 29052-29058. S. D. Orwig, Y. L. Tan, N. P. Grimster, Z. Yu, E. T. Powers, J. W. Kelly and R. L. Lieberman, Biochemistry, 2011, 50, 10647-57

R. L. Lieberman, B. A. Wustman, P. Huertas, A. C. Powe, C. W. Pine, R. Khanna, M. G. Schlossmacher, D. Ringe and G. A. Petsko, Nat. Chem. Biol., 2007, 3, 101-107.

Z. Luan, K. Higaki, M. Aguilar-Moncayo, H. Ninomiya, K. Ohno, M. I. García-Moreno, C. Ortiz Mellet, J. M. García Fernández and Y. Suzuki, ChemBioChem, 2009, 10, 2780-92. C. Baudoin-Dehoux, T. Castellan, F. Rodriguez, A. Rives, F. Stauffert, V. Garcia, T. Levade, P. Compain and Y. Génisson, Molecules, 2019, 24, 354. F. Stauffert, J. Serra-Vinardell, M. Gómez-Grau, H. Michelakakis, I. Mavridou, D. Grinberg, L. Vilageliu, J. Casas, A. Bodlenner, A. Delgado and P. Compain, Org. Biomol. Chem., 2017, 15, 3681-3705.

A. Sevšek, L. Šrot, J. Rihter, M. Čelan, L. Q. van Ufford, E. E. Moret, N. I. Martin and R. J. Pieters, ChemMedChem, 2017, 12, 483-486.

E. F. Pettersen, T. D. Goddard, C. C. Huang, G. S. Couch, D. M. Greenblatt, E. C. Meng and T. E. Ferrin, J. Comput. Chem., 2004, 25, 1605-1612.

40
Res., 2000, 28, 235-42.

H. Dvir, M. Harel, A. a McCarthy, L. Toker, I. Silman, A. H. Futerman and J. L. Sussman, EMBO Rep., 2003, 4, 704-9.

E. C. Meng, E. F. Pettersen, G. S. Couch, C. C. Huang and T. E. Ferrin, BMC Bioinformatics, 2006, 7, 1-10.

T. Castellan, C. Santos, F. Rodriguez, M. L. Lepage, Y. Liang, A. Bodlenner, P. Compain, Y. Génisson, C. Dehoux and S. Ballereau, Bioorg. Med. Chem. Lett., 2020, 30, 126796.

S. F. Sousa, A. J. M. Ribeiro, J. T. S. Coimbra, R. P. P. Neves, S. A. Martins, N. S. H. N. Moorthy, P. A. Fernandes and M. J. Ramos, Curr. Med. Chem., 2013, 20, 2296-2314.

R. Thomsen and M. H. Christensen, J. Med. Chem., 2006, 49, 3315-3321. 